\title{
Numerical Modeling of Biomass and Solid Waste-Based Syngas Fuels Combustion
}

\author{
Chaouki Ghenai $^{a, *}$, Tareq Samir Zaki Salameh ${ }^{a}$, Isam Janajreh ${ }^{b}$ \\ ${ }^{a}$ Sustainable and Renewable Energy Engineering Department, College of Engineering, University of Sharjah, UAE \\ ${ }^{b}$ Masdar Institute of Science and Technologies, Mechanical and Material Program, Abu Dhabi, UAE
}

\begin{abstract}
The combustion of syngas fuels in gas turbine combustor is presented in this paper. The principal objective is to test the performance of the combustion process using non-conventional fuels produced from the gasification of biomass and solid waste. Three dimensional syngas combustion simulations were performed in this study. The mixture fraction/pdf and the P1 radiation models were used to model the non-premixed turbulent combustion. The syngas fuels are derived from the gasification of wood saw dust, wooden pellet and nonrecycled solid waste plastics. The effect of syngas fuel compositions and lower heating values on the combustion process was investigated. The power from the combustor was kept constant at $60 \mathrm{~kW}$ for all the syngas fuels tested in this study. The results show a decrease of the peak gas temperature inside the combustor for the syngas fuels compared to conventional fossil gas fuel. The peak gas temperature inside the combustor decreases by $16.1 \%, 19.8 \%$, and $17.2 \%$ respectively for the syngas 1 (derived from plastic waste), syngas 2 (derived from wood saw dust) and syngas 3 (derived from wooden pellets) compared to natural gas fuel. The highest average NO mass fraction at the combustor exit was obtained with syngas 1 (plastic waste) compared to the other syngas fuels due to the high lower heating value. The highest average $\mathrm{CO}_{2}$ mass fraction at the exit of the combustor was obtained with syngas 2 (wood saw dust) compared to the other syngas due to the high amount of $\mathrm{CO}_{2}$ in the syngas fuel (15\%).
\end{abstract}

Key words: Alternative and Renewable Fuels, Syngas, Plastic Waste, Wood Saw Dust, Wood Pellets, Gasification, Combustion

\section{Introduction}

Natural gas composed primarily of methane is the conventional gas fuel used to power gas turbines engines. The development and use of renewable and alternative fuels like syngas and biogas presents certain challenges that need to be addressed. The syngas and biogas alternative fuels have different chemical compositions compared to natural gas fuels. Natural gas is a fossil fuel composed mainly of methane $\left(\mathrm{CH}_{4}\right)$. Biogas is produced trough biochemical process (anaerobic digestion) and contains mainly methane $\left(\mathrm{CH}_{4}\right)$ and carbon dioxide $\left(\mathrm{CO}_{2}\right)$. Syngas fuels produced through thermal chemical process (gasification of biomass, coal and solid waste) are composed of methane $\left(\mathrm{CH}_{4}\right)$, Hydrogen $\left(\mathrm{H}_{2}\right)$, carbon monoxide $(\mathrm{CO})$, carbon dioxide $\left(\mathrm{CO}_{2}\right)$, nitrogen $\left(\mathrm{N}_{2}\right)$ and water $\left(\mathrm{H}_{2} \mathrm{O}\right)$. The alternative and renewable syngas and biogas fuels have also different lower heating values (calorific values or energy densities $\mathrm{kJ} / \mathrm{kg}$ ). The heating values of syngas and biogas fuels are much lower than

${ }^{*}$ Corresponding author

E-mail: cghenai@sharjah.ac.ae

(C) 2016 International Association for Sharing Knowledge and Sustainability

DOI: $10.5383 /$ ijtee.11.02.006 the heating value of natural gas. In order to meet these challenges, we need to understand the physical and chemical processes of syngas and biogas combustion. Information regarding flame shape, flame speed, gas temperatures and pollutant emissions such as $\mathrm{NOx}_{\mathrm{x}}$ and $\mathrm{CO}_{2}$ for a range of alternative fuels compositions and heating values are needed for the design of gas turbine combustors.

Several studies can be found in the literature on syngas fuel combustion. Giles et al. [1] and Ghenai et al [2] performed a numerical investigation on the effects of syngas composition and diluents on the structure and emission characteristics of syngas diffusion flame. Lean premixed combustion of hydrogensyngas/methane fuel mixtures was investigated experimentally by Alavandi and Agarwal [3]. Experimental study on the fundamental impact of firing syngas in gas turbines was performed by Oluyede [4]. The results show that volume fraction of hydrogen content in syngas fuel significantly impact the life of hot sections as a result of higher flame temperature for 
hydrogen rich fuels and also the moisture content of combustion products. The challenges of fuel diversity while maintaining superior environmental performance of gas turbine engines was addressed by Rahm et al. [5]. They reviewed the combustion design flexibility that allows the use of a broad spectrum of gas and liquid fuel including emerging synthetic choices. Gases include ultra-low heating value process gas, syngas, ultra-high hydrogen or higher heating capability fuels. The integration of heavy-duty gas turbine technology with synthetic fuel gas processes using low-value feed stocks in global power generation marketplace was covered by Brdar and Jones [6]. In this paper they summarized the experience gained from several syngas projects and lessons learned that continue to foster cost reductions and improve the operational reliability of gas turbine. They concluded that further improvements in system performance and plant design are needed in the future. The challenges for application of syngas in power generation plants and the trend of engine technologies were investigated by Hagos et al. [7]. Three different syngas from the gasification product were used in their studies. The results show that proper optimization of major engine variables should be done in the current engine technology using syngas fuels. Two different gases derived from gasification of waste wood chips and turkey feathers to simulate the non-premixed turbulent combustion were investigated by Kwiatkowski et al. [8]. The results show a difference between the wood derived syngas combustion and the feathers derived fuels. For the feather derived fuels, the thermal and prompt and $\mathrm{N}_{2} \mathrm{O}$ path of nitric oxides formation were marginal and the dominant source of $\mathrm{NO}$ was fuel bound nitrogen. Azimov et al. [9] investigated the combustion characteristics of syngas and natural gas in micro-pilot ignited dual-fuel engine. The main objective of this study was to investigate the premixed combustion in pilot-ignited supercharged dual-fuel engine, fueled with different types of gaseous fuels under various equivalence ratios.

Syngas are renewable gaseous fuel derived from gasification of Biomass and solid waste. The syngas produced can be burned and used for different applications: (1) electricity generation, (2) heat and combined heat and power generation CHP, and (3) Transportation: internal combustion engines. The benefits of the using syngas are: (1) increase energy security: syngas offsets non-renewable resources (coal, oil, NG), (2) great potential for the production of syngas using a renewable energy sources, and (3) emissions reduction.

This study focus on the combustion performance and emissions of syngas fuels derived from Plasma gasification (See Fig. 1). The syngas are produced using plasma gasification of biomass and solid waste. The gasification is a process producing gas composed mostly of hydrogen and carbon monoxide. Plasma gasification can be used to control the produced syngas composition and lower heating value of the syngas by supplying the external energy for material gasification (Fig. 1). The plasma gasification will also help to reduce the unwanted contaminant like tar, the carbon dioxide $\mathrm{CO}_{2}$, methane $\mathrm{CH}_{4}$ and higher hydrocarbon. High concentrations of hydrogen and carbon monoxides, and low concentrations of methane can be obtained for the syngas fuels using plasma gasification.

The design of combustion systems using alternative fuels such as syngas fuel can take advantage of CFD analysis to optimize the efficiency of the combustion system with respect to the limitations of pollutants emission. The aim of this work is to analyze the fundamental impacts of firing syngas fuels in gas turbine combustor and predict the changes in the firing temperature and emissions with respect to natural gas or methane.

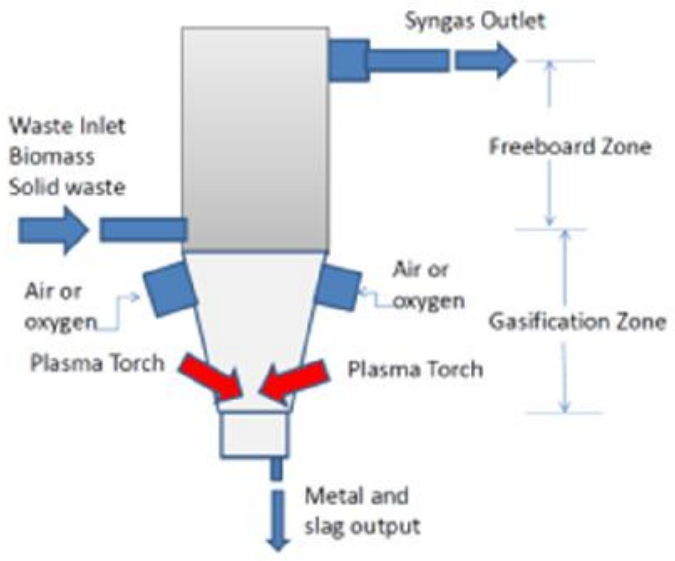

Figure 1 Syngas Production from Plasma Gasification of Biomass and Solid Waste

\section{Combustion Modeling: Governing Equations}

The governing equations for the syngas and natural gas fuels combustion consist of (1) equation of conservation of mass or continuity equation, (2) three equations for the conservation of momentum, (3) the energy equation, (4) two equations for turbulence modeling ( $\mathrm{k}$ - turbulence model- turbulent kinetic energy $k$ and the dissipation rate of the turbulent kinetic energy

, (5) mixture fraction equation (mixture fraction/pdf model for non-premixed combustion or diffusion flame modeling), and (6) equation for the flame radiation modeling. The mean equations for steady turbulent non-premixed combustion [2] are given by:

Continuity:

$$
\frac{\partial \overline{\rho u_{i}}}{\partial x_{i}}=0
$$

\section{Momentum Equation:}

$$
\frac{\partial\left(\overline{\rho u_{i} u_{j}}\right)}{\partial x_{j}}=-\frac{\partial \bar{P}}{\partial x_{i}}+\frac{\partial\left(\overline{t_{i j}}+\overline{\tau_{i j}}\right)}{\partial x_{j}}
$$

Energy Equation:

$\frac{\partial(\overline{(\rho E+p) u j})}{\partial x_{j}}=\frac{\partial\left[\left(k_{e f f}\right) \frac{\partial \bar{T}}{\partial x_{j}}-\sum_{j} h_{j} J_{j}+\left(\bar{\tau}_{e f f} u_{j}\right)\right]}{\partial x_{j}}+S_{h}$

Where $E$ is the total energy $\left(E=h-p /+v^{2} / 2\right.$ where $h$ is the sensible enthalpy), $\mathrm{k}_{\text {eff }}$ is the effective conductivity $(\mathrm{k}+\mathrm{kt}$ : laminar and turbulent thermal conductivity), $\mathrm{J}_{\mathrm{j}}$ is the diffusion flux of species $j$, and $S_{h}$ is the term source that includes the heat of chemical reaction, radiation and any other volumetric heat sources.

Turbulent Kinetic Energy Equation:

$\frac{\partial\left(\overline{\rho k u_{j}}\right)}{\partial x_{j}}=\frac{\partial\left[\left(\mu+\frac{\mu_{t}}{\sigma_{k}}\right) \frac{\partial \bar{k}}{\partial x_{j}}\right]}{\partial x_{j}}+G_{k}-\overline{\rho \varepsilon}$ 
Where $\sigma_{\mathrm{k}}=1$ and $\mathrm{G}_{\mathrm{k}}$ is the production of the turbulent kinetic energy.

\section{Dissipation of the Kinetic Energy}

$\frac{\partial\left(\overline{\rho \varepsilon u_{j}}\right)}{\partial x_{j}}=C_{\varepsilon 1} \frac{\bar{\varepsilon}}{k} G_{k}+\frac{\partial\left[\left(\mu+\frac{\mu_{t}}{\sigma_{\varepsilon}}\right) \frac{\partial \bar{\varepsilon}}{\partial x_{j}}\right]}{\partial x_{j}}-C_{\varepsilon 2} \frac{\bar{\rho} \frac{\overline{\varepsilon^{2}}}{k}}{k}$

Where $\mathrm{C}_{\varepsilon 1}=1.44, \mathrm{C}_{\varepsilon 2}=1.92$, and $\sigma_{\varepsilon}=1.3$

\section{Mixture Fraction $f$ :}

For non-premixed combustion modeling the PDF/mixture fraction model is used in this study. The equation for the conserved scalar or mixture fraction $(f)$ is solved, and individual component concentrations are derived from the predicted mixture fraction distribution.

The mixture fraction equation is given by:

$\frac{\partial\left(\overline{\rho f u_{j}}\right)}{\partial x_{j}}=\frac{\partial\left[\left(\frac{\mu_{t}}{\sigma_{t}}\right) \frac{\partial \bar{f}}{\partial x_{j}}\right]}{\partial x_{j}}+S_{m}$

The mixture fraction, $f$ id function of elemental mass fraction and given by:

$f=\frac{Z_{k}-Z_{k, o}}{Z_{k, F}-Z_{k, o}}$

Where $Z_{k}$ is the element mass fraction of element $k$. Subscripts $\mathrm{F}$ and $\mathrm{O}$ denote fuel and oxidizer inlet stream values, respectively. The equilibrium chemistry PDF model is used in this study. The equilibrium system consists of 13 species $(\mathrm{C}$, $\mathrm{CH}_{4}, \mathrm{CO}, \mathrm{CO}_{2}, \mathrm{H}, \mathrm{H}_{2}, \mathrm{H}_{2} \mathrm{O}, \mathrm{N}_{2}, \mathrm{NO}, \mathrm{O}, \mathrm{O}_{2}, \mathrm{OH}, \mathrm{HO} 2$ ). The chemistry is assumed to be fast enough to achieve equilibrium.

\section{P-1 Radiation Model - Radiation Flux Equation:}

The radiation from the flame is modeled using the $\mathrm{P}-1$ radiation model. The radiation model is based on the expansion of the radiation intensity into an orthogonal series of spherical harmonics (Cheng [10] and Siegel and Howell [11]). The P-1 radiation model is the simplest case of the P-N model. If only four terms in the series are used, the following equation is obtained for the radiation flux:

$q_{r}=-\frac{1}{3\left(a+\sigma_{s}\right)-C \sigma_{s}} \nabla G$

Where $\mathrm{a}$ is the absorption coefficient, $\sigma_{\mathrm{S}}$ is the scattering coefficient, $\mathrm{G}$ is the incident radiation, and $\mathrm{C}$ is the linearanisotropic phase function coefficient (Cheng [10] and Siegel and Howell [11).

The governing equations are solved using the finite volume method and the first order upwind technique. The solution procedure for a single-mixture-fraction system was to: (1) complete the calculation of the PDF look-up tables first, (2) start the reacting flow simulation to determine the flow files and predict the spatial distribution of the mixture fraction, (3) continue the reacting flow simulation until a convergence solution was achieved, and (4) determine the corresponding values of the temperature and individual chemical species mass fractions from the look-up tables. The convergence criteria were set to $10^{-3}$ for the continuity, momentum, turbulent kinetic energy, dissipation rate of the turbulent kinetic energy, and the mixture fraction. For the energy and the radiation equations, the convergence criteria were set to $10^{-6}$.

\section{Can Combustor, Boundary Conditions and Mesh}

Figure 2 show the geometry model used for the gas turbine can combustor. The size of the combustor is $590 \mathrm{~mm}, 250 \mathrm{~mm}$, and $230 \mathrm{~mm}$ respectively in the $\mathrm{z}, \mathrm{y}$ and $\mathrm{x}$ directions. The primary inlet air is guided by vanes to give the air a swirling velocity component (See Figure 2). The primary air is injected with a velocity of $10 \mathrm{~m} / \mathrm{s}$, temperature of $300 \mathrm{~K}$, turbulence intensity of $10 \%$, and mixture fraction $\mathrm{f}=0$. The injection diameter of the primary air is $85 \mathrm{~mm}$. The fuel is injected through six fuel inlets in the swirling primary air flow (near the vanes region as shown in Figure 2). The fuel velocity or the volume flow rate (see Table 1) were varied to keep the same combustor power $P=60 \mathrm{~kW}$ for the four fuels tested in this study (note the syngas with low lower heating value has high fuel velocity of volume rate rate). The fuel was injected at a temperature of $300 \mathrm{~K}$, with a turbulence intensity of $10 \%$, and mixture fraction $\mathrm{f}=1$. The fuel injector diameter is $4.2 \mathrm{~mm}$. A secondary air or dilution air is injected at 0.1 meters from the fuel injector to control the flame temperature and NOx emissions. The secondary air is injected in the combustion chamber though six side air inlets each with a diameter of $16 \mathrm{~mm}$ (see Figure 2). The secondary air is injected with a velocity of $6 \mathrm{~m} / \mathrm{s}$, temperature of $300 \mathrm{~K}$, turbulence intensity of $10 \%$, and a mixture fraction $f=0$. The injection diameter of the secondary air is $16 \mathrm{~mm}$. The can combustor outlet has a rectangular shape (see Figure 2) with an area of $0.0150 \mathrm{~m}^{2}$. A quality mesh was generated for the can combustor (see Figure 2). The mesh generated consists of 106,651 cells or

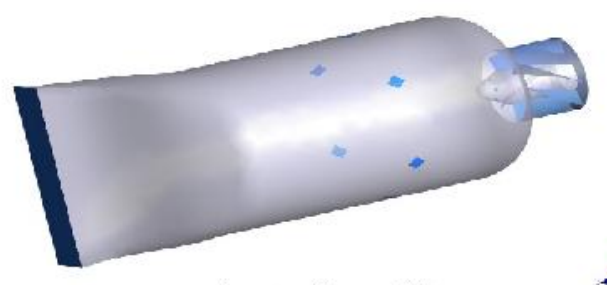

elements.

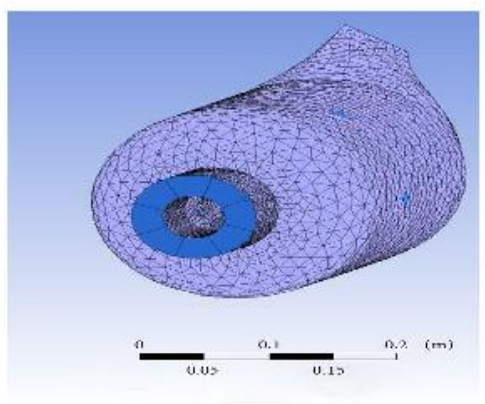

Figure 2 Combustor Geometry Model 


\section{Syngas Fuel Compositions and Lower Heating Values}

The syngas compositions and lower heating values are shown in Table 2. The syngas are produced using plasma gasification of biomass and solid waste [12]. Gasification is a process producing gas composed mostly of hydrogen and carbon monoxide (syngas or synthetic gas) as shown in Table 2. Plasma gasification was used to control the produced syngas composition and lower heating value of the syngas by supplying the external energy (high energy in short time) for material gasification. The plasma gasification will also help to reduce the unwanted contaminant like tar, the carbon dioxide $\mathrm{CO}_{2}$, methane $\mathrm{CH}_{4}$ and higher hydrocarbon [12]. The arc powers for the plasma gasification of solid materials were kept at $140 \mathrm{~kW} \mathrm{[12].} \mathrm{The} \mathrm{composition} \mathrm{of} \mathrm{the} \mathrm{syngas} \mathrm{fuel} \mathrm{produced} \mathrm{from} \mathrm{plasma} \mathrm{gasification}$ of wood saw dust, wooden pellets $6 \mathrm{~mm}$ in diameter and $6 \mathrm{~mm}$ long, waste polyethylene plastics (80\% high density polyethylene and $20 \%$ low density polyethylene) are shown in Table 2 . The data in Table 2 show high concentrations of hydrogen and carbon monoxides, low concentrations of methane and lower heating values of about $10 \mathrm{MJ} / \mathrm{m}^{3}$ for all the syngas produced from the three solid materials (plastic waste, wooden pellets and wood saw dust) through plasma gasification.

Table 1 Fuel and Air Injection Conditions

\begin{tabular}{|l|l|l|l|l|}
\hline Fuel and Air Injection Conditions & Natural Gas & $\begin{array}{l}\text { Syngas1 } \\
\text { Waste Plastic }\end{array}$ & $\begin{array}{l}\text { Syngas2 } \\
\text { Wood Saw Dust }\end{array}$ & $\begin{array}{l}\text { Syngas3 } \\
\text { Wooden Pellets }\end{array}$ \\
\hline Primary air velocity $(\mathbf{m} / \mathbf{s})$ & 10 & 10 & 10 & 10 \\
\hline Secondary air velocity $(\mathbf{m} / \mathbf{s})$ & 6 & 6 & 6 & 6 \\
\hline Fuel velocity $(\mathbf{m} / \mathbf{s})$ & 20.3 & 69.40 & 75.11 & 73.1 \\
\hline LHV $\left(\mathbf{M J} / \mathbf{m}^{\mathbf{3}}\right)$ & 37 & 10.8 & 10.1 & 10.3 \\
\hline Combustor Power $(\mathbf{k W})$ & 60 & 60 & 60 & 60 \\
\hline
\end{tabular}

Table 2 Fuel Compositions and Lower Heating Values

\begin{tabular}{|l|l|l|l|l|}
\hline Fuel Compositions (Weight \%) & Natural Gas & $\begin{array}{l}\text { Syngas1 } \\
\text { Waste Plastic }\end{array}$ & $\begin{array}{l}\text { Syngas2 } \\
\text { Wood Saw Dust }\end{array}$ & $\begin{array}{l}\text { Syngas3 } \\
\text { Wooden Pellets }\end{array}$ \\
\hline Hydrogen $\mathbf{H}_{\mathbf{2}}$ & 0 & 41.6 & 44.8 & 48.1 \\
\hline Carbon monoxide CO & 0 & 49.7 & 39.2 & 40 \\
\hline Carbon dioxide CO & 0 & 7.4 & 15.0 & 11 \\
\hline Methane $\mathbf{C H}_{\mathbf{4}}$ & 0 & 0 & 0.9 & 0.1 \\
\hline Oxygen $\mathbf{O}_{\mathbf{2}}$ & 95 & 1.3 & 0.1 & 0.8 \\
\hline Ethane $\mathbf{C}_{\mathbf{2}} \mathbf{H}_{\mathbf{6}}$ & 0 & 0 & 0 & 0 \\
\hline $\mathbf{H}_{\mathbf{2}} / \mathbf{C O}$ & 5 & 0.84 & 1.14 & 1.20 \\
\hline $\left.\mathbf{L H V} \mathbf{M J} / \mathbf{m}^{\mathbf{3}}\right)$ & 0 & 10.8 & 10.1 & 10.3 \\
\hline
\end{tabular}

\section{Results}

The combustion performance and emissions of natural gas and syngas fuels in gas turbine can combustor is presented in this paper. The CFD analysis includes the effect of syngas fuel composition and lower heating value on the combustion process. The range of constituents volume fractions for the selected syngas fuels are (1) Hydrogen $41.6 \%-48.15 \%$, (2) carbon monoxide $(\mathrm{CO})=39.2 \%-49.7 \%$, (3) carbon dioxide $\left(\mathrm{CO}_{2}\right)=7.45-15 \%$, (4) methane $\left(\mathrm{CH}_{4}\right)=0-0.9 \%$, and oxygen $\mathrm{O}_{2}=0.1-1.3 \%$. The hydrogen to carbon monoxide fraction for the syngas fuel is between $0.84-1.20$. The lower heating value of the natural gas fuel is 3.4 to 3.6 times the heating values of the syngas fuels. The syngas volume flow rate of the syngas was increased by $3.4-3.6$ compared to the natural gas volume flow rate to keep the same power from the combustor as shown in Table 1. The contours of the gas temperature for the combustion of natural gas and syngas fuel in gas turbine can combustor are shown in Figure 3. The combustion of natural gas fuel shows a maximum gas temperature of $2111^{\circ} \mathrm{K}$. The predicted gas temperature for the natural gas fuel was compared to the adiabatic flame temperature $\left(\mathrm{T}_{\mathrm{ad}}=2200 \mathrm{~K}\right)$. The predicted maximum temperature inside the can combustor compare well with the theoretical adiabatic flame temperature. The natural gas fuel combustion shows a peak gas temperature in the primary reaction zone. The fuel from the six injectors is first mixed in the swirling air before burning in the primary reaction zone.
After the primary reaction zone, the gas temperature decreases due to the dilution of the flame with secondary air flow. Figure 4 show the velocity vectors and the recirculation zones in the primary reaction zone. The primary air is injected in the $\mathrm{z}$ direction with an initial velocity of $10 \mathrm{~m} / \mathrm{s}$. The primary air is accelerated to $17.83 \mathrm{~m} / \mathrm{s}$ at the entrance of the combustors due to the presence of swirllers vanes [2]. Recirculation regions are produced in the fuel injection region. This helps to get a good air fuel mixing in the primary reaction zone as shown in Figure 4. This will help to burn the fuel efficiently and reduce the emissions from the combustor. The static temperature contours (see Figure 3) in the $\mathrm{x}-\mathrm{z}$ plane show that the gas temperature inside the can combustor decreases for all the syngas fuels compared to the natural gas fuel. This is due to the amount of inert gas $\mathrm{CO}_{2}$ present in the syngas fuel. For example, the syngas derived from the gasification of wood saw dust has $15 \%$ of carbon dioxide. The dilution of hydrocarbon syngas fuel $\left(\mathrm{H}_{2}\right.$ and $\mathrm{CO})$ with carbon dioxide $\left(\mathrm{CO}_{2}\right)$ will reduce the flame temperature. The carbon dioxide $\mathrm{CO}_{2}$ and other inert gas such as nitrogen $\mathrm{N}_{2}$ in the fuel will absorb the heat from the combustion process (they are flame inhibitors) and reduce the flame temperature. The presence of carbon dioxide and nitrogen in the syngas fuel will reduce the burning velocity [10] of the flame, the burning rate and will affect the flame shape (See the flame for syngas in Fig. 3). Syngas syngas-air mixtures combustion produce lower gas temperature inside the combustor compared to natural gas fuel. The gas temperature for syngas fuel combustion depends on the carbon dioxide and other inert gas volume fractions. The peak gas temperature 
decreases as the $\mathrm{CO}_{2}$ volume fractions in the fuel increases and the lower heating values decreases. The peak gas temperature inside the combustor decreases by $16.1 \%, 19.8 \%$ and $17.2 \%$ respectively for the syngas derived from the gasification of plastic waste, wood sawdust and wooden pellets compared to natural gas fuel.
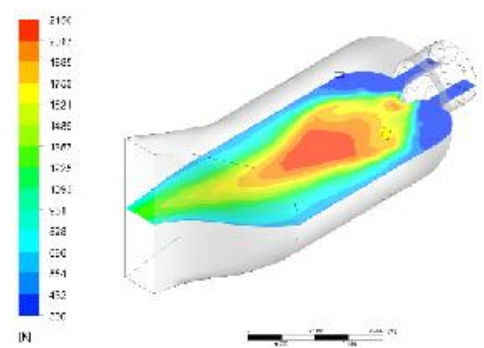

(a)
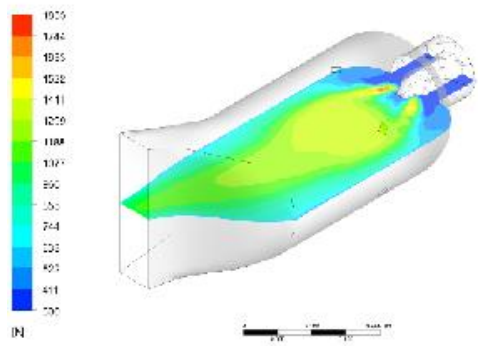

(b)
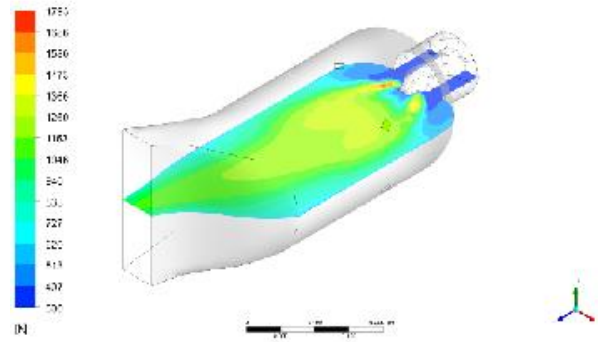

(c)
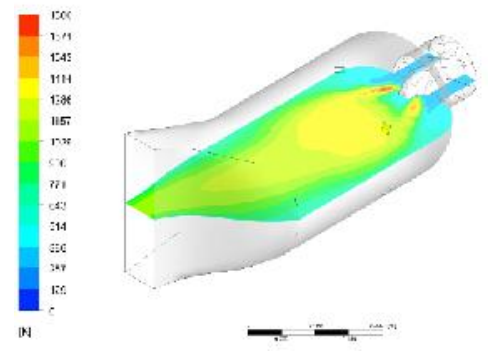

(d)

Figure 3 Contours of Temperature in the Z-X Plane (A) Natural Gas, (B) Syngas 1 (Plastic Waste), Syngas 2 (Wood Saw Dust), and (D) Syngas (Wooden Pellets)
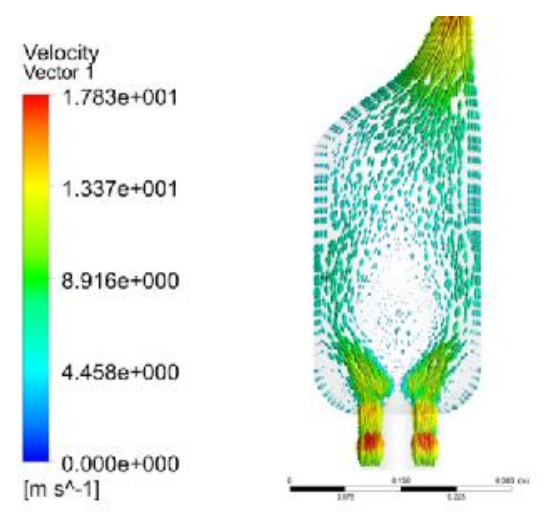
Figure 4 Velocity Vectors Colored By the Velocity Magnitude in
the X-Z Plane

The NOx emissions from natural and syngas gas fuel combustion were also determined. The $\mathrm{NO}_{\mathrm{x}}$ concentrations emitted from combustion systems are generally low. The NOx chemistry has negligible influence on the predicted flow field, temperature, and major combustion product concentrations. The NOx model used in this study was a postprocessor to the main combustion calculation. First the reacting flows are simulated without $\mathrm{NOx}$ emissions until the convergence of the main combustion calculation was obtained; after that the desired $\mathrm{NO}_{\mathrm{X}}$ models were enabled to predict the $\mathrm{NO}_{\mathrm{X}}$ emissions. The contours of NO mass fraction inside the can combustor are shown in Figure 5. The NO mass fraction inside the combustor decreases when the baseline fuel (natural gas) is replaced with syngas fuel with lower heating value. The thermal $\mathrm{NO}_{\mathrm{x}}$ emission is function of the gas temperature. Higher is the temperature, higher is the NOx mass fractions. The presence of non- combustible constituents in the syngas such as carbon dioxides reduces the temperature of the flame and consequently the NO mass fractions. This reduction is proportional to the amount of inert constituents in syngas fuel.

The effect of syngas fuel compositions and lower heating values on the combustion and emissions characteristics at the exit of the combustor was also determined in this study. The average flame temperature, $\mathrm{NO}$ mass fractions, and $\mathrm{CO}_{2}$ mass fractions at the exit of the combustor were determined. The average flame temperature at the exit of the combustor decreases from $950^{\circ} \mathrm{K}$ for natural gas fuel combustion to $926^{\circ} \mathrm{K}, 924^{\circ} \mathrm{K}$, and $925^{\circ} \mathrm{K}$ respectively for syngas 1 (plastic waste), syngas 2 (wood saw dust), and syngas 3 (wooden pellets). The average NO mass fractions for the syngas fuels at the exit of the combustor are shown in Figure 6.a. The syngas derived from the gasification of waste plastic shows high NO mass fraction at the exit of the combustor due to the high gas temperature inside the combustor (see Fig. 3). The syngas derived from waste plastic has also the highest lower heating value compared to the other syngas fuels. Figure 6 .b shows the average $\mathrm{CO}_{2}$ mass fraction at the exit from the combustor. The syngas fuel derived from the gasification of wood saw dust shows a high $\mathrm{CO}_{2}$ mass fraction at the exit of the combustor due to the high $\mathrm{CO}_{2}$ content in the fuel $(15 \%$ as shown in Table 2). 


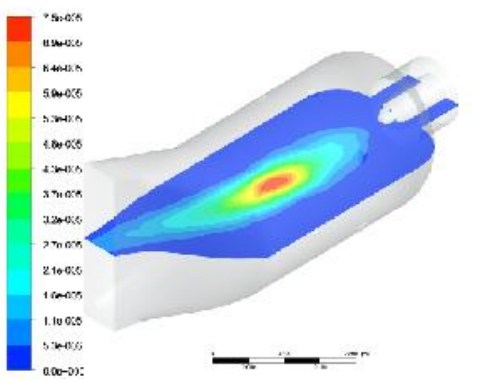

(a)

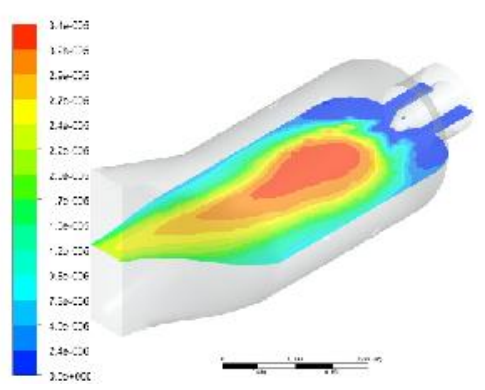

(b)

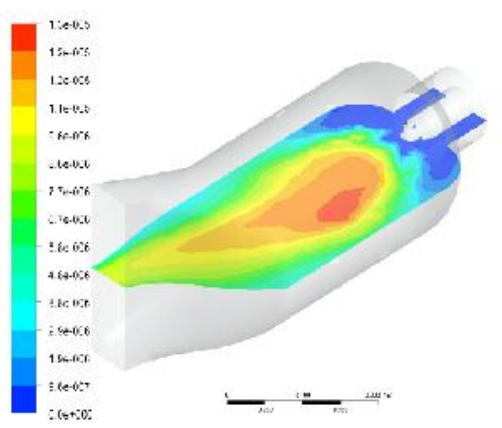

(c)
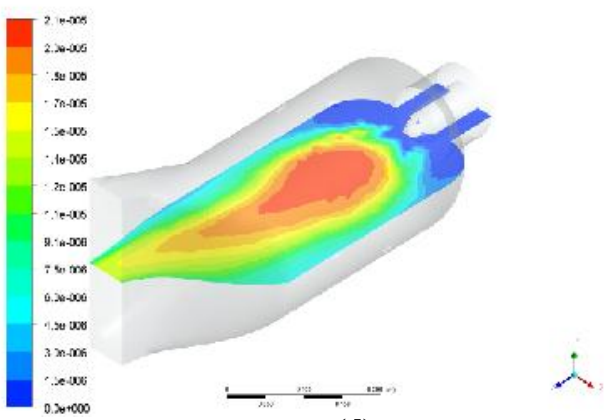

(d)

Figure 5 Contours of NO Mass Fraction Inside the Can Combustor (A) Natural Gas, (B) Syngas 1 (Plastic Waste), (C) Syngas 2 (Wood Saw Dust), and (D) Syngas (Wooden Pellets)

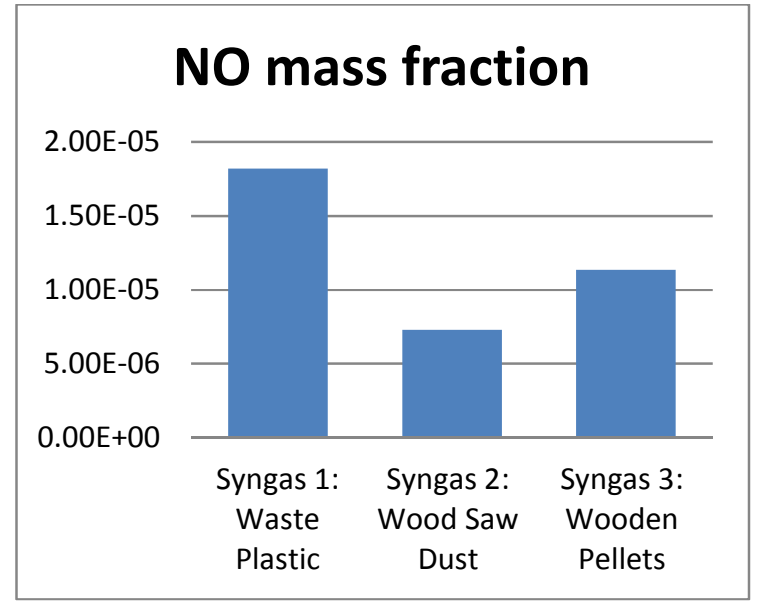

(a)

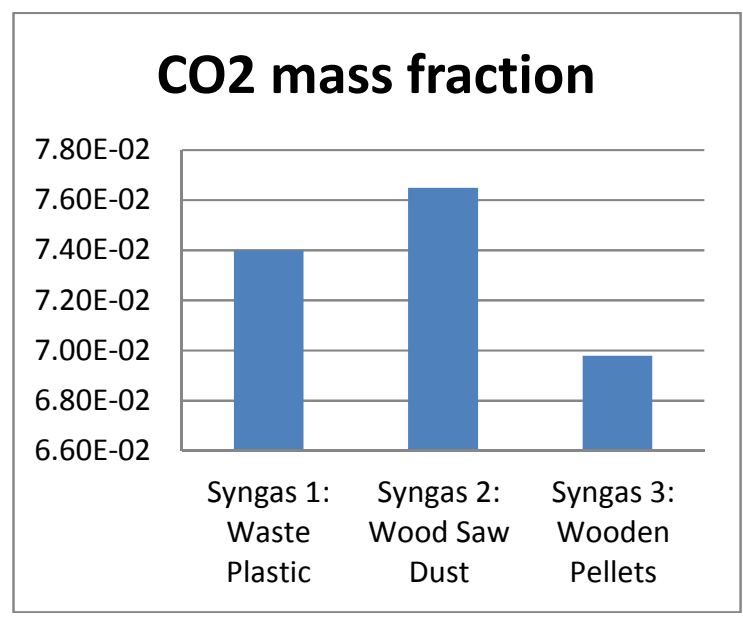

(b)

Figure 6 Average Mass Fractions at the Exit of the Combustor (A) $\mathrm{NO}$ and (B) $\mathrm{CO}_{2}$

\section{Conclusion}

Three dimensional CFD analyses of natural gas, and syngas fuels combustion in gas turbine can combustor is presented in this study. The syngas gas fuels are obtained from plasma gasification of waste plastic, wood saw dust and wooden pellets. The syngas fuels with different fuel compositions $\left(\mathrm{H}_{2} / \mathrm{CO}=0.81-1.20\right)$ and lower heating values $(10.1-10.8$ $\mathrm{MJ} / \mathrm{m}^{3}$ ) were tested in this study. The fuel flow rate was varied for different fuels to keep constant the power from the combustor $(\mathrm{P}=60 \mathrm{~kW})$. The effect of the syngas fuel composition, and fuel heating values on flame shape, flame temperature, carbon dioxide $\left(\mathrm{CO}_{2}\right)$, and nitrogen oxides ( $\mathrm{NOx}$ ) emissions was determined in this study:

1. The flame temperature for the syngas fuels with different compositions and low heating values show a lower temperature compared to the adiabatic flame temperature of natural gas. The inert gas $\left(\mathrm{CO}_{2}\right)$ in the syngas fuels cools down the reaction by absorbing the energy from the combustion of hydrocarbon fuels. 
2. The peak flame temperature inside the can combustor for the syngas fuel derived from wood saw dust was $\mathrm{T}_{\max }=17830$ ${ }^{\circ} \mathrm{K}$. The maximum flame temperature for the syngas fuel derived from wood saw dust decreased by $17 \%$ compared to the maximum temperature for the natural gas combustion $\left(\mathrm{T}_{\max }=2111^{\circ} \mathrm{K}\right)$. This is due to the presence of high $\mathrm{CO}_{2}$ concentration $(15 \%)$ in the fuel for the syngas fuel derived from wood saw dust. The presence of high concentrations of inert gas in the fuel will reduce further the flame temperature for syngas fuels.

3. The flame shape and the temperature distribution inside the can combustor depend on the $\mathrm{H}_{2} / \mathrm{CO}$ ratio, the amount of inert gas $\left(\mathrm{CO}_{2}\right)$, and lower heating values of the syngas fuels. Shorter flame with high turbulent burning velocities and close to the fuel injection regions are obtained with syngas fuels with high hydrogen contents. The gas temperature increases with the hydrogen contents in the syngas fuels but the presence of inert gas such as $\mathrm{CO}_{2}$ reduces the flame temperature, the flame turbulent burning velocity, and the burning rate.

4. The maximum gas temperature inside the combustor for the syngas fuel derived from the gasification of waste plastic was $\mathrm{T}_{\max }=1823^{\circ} \mathrm{K}$. The maximum flame temperature for the syngas fuel derived from plastic waste decreased by $14 \%$ compared to the maximum temperature for the natural gas combustion $\left(\mathrm{T}_{\max }=2111^{\circ} \mathrm{K}\right)$. The syngas fuel derived from waste plastic has the highest lower heating values (LHV = $10.8 \mathrm{MJ} / \mathrm{m}^{3}$ ) compared to the syngas gas derived from the gasification of wood saw dust and wooden pellets.

5. The emissions from syngas fuel combustion vary depending on the composition of syngas and lower heating values. High average NO mass fraction at the exit from the combustor was obtained with the syngas gas derived from plastic waste due to the high gas temperature inside the combustor $\left(\mathrm{T}_{\max }\right.$ $=1823^{\circ} \mathrm{K}$ ). For the carbon dioxide $\mathrm{CO}_{2}$, the highest average concentration at the exit from the combustor was obtained with the syngas fuel derived from wood saw dust due to the high amount of $\mathrm{CO}_{2}$ in the fuel (15\%).

\section{References}

[1] Giles, D., E., Som, S., and Aggarwal, S.K., $\mathrm{NO}_{x}$ emission characteristics of counterflow syngas diffusion flames with airstream dilution, Fuel, volume 85, Issues 12-13, 2006
[2] Ghenai, Combustion of syngas fuel in gas turbine can combustor, Advances in Mechanical Engineering, Volume 2010, Article ID 342357, 13 pages, 2010.

[3] Alavandi, S.K., Agarwal, A.K. , Experimental study of combustion of hydrogen-syngas/methane fuel mixtures in a porous burner, International Journal of Hydrogen Energy, Volume 33, Issue 4, pp. 1407, 2008

[4] Oluyede, E.O., Fundamental impact of firing syngas in gas turbines, Gas Turbine Industrial Fellowship Program, Project Report, Electric Power Research Institute, Charlotte, 2006

[5] Rahm, S., Goldmeer, J., Moilere, M., Eranki, A., Addressing gas turbine fuel flexibility, Power-Gen Middle East conference in Manama, Bahrain on February 17-19, 2009.

[6] Brdar R.D., and Jones R. M., GE IGCC Technology and Experience with Advanced gas turbines, GE Power Systems, GER-4207, 2000.

[7] Hagos, F.Y., Aziz, R.A., and Sulaiman, S.A., Trends of Syngas as a fuel in internal combustion engines, Advances in Mechanical Engineering, Volume 2014, Article ID 401587, 10 pages, 2014.

[8] Kwiatkowski, K., Dudynski, M., Bajer, K. Combustion of low calorific biomass syngas, Flow Turbulence Combust, 91: pp 749-772, 2013.

[9] Azimov, U, Tomita, E., Kawahara, N., and Dol, S.S., Combustion characteristics of synga and natural gas in micro-pilot ignited dual-fuel engine, World Academy of Science, Engineering and Technology, Vol 6, 2012.

[10] P. Cheng, Two-dimensional radiating gas flow by a moment method. AIAA Journal, 2:1662-1664, 1964.

[11] R. Siegel and J. R. Howell, Thermal radiation heat transfer. Hemisphere Publishing Corporation, Washington DC, 1992.

[12] Hrabovsky, M., Plasma aided gasification of biomass, organic waste and plastics, $30^{\text {th }}$ OCPIG, August 28th - September $2^{\text {nd }}, 2011$, Belfast, Northern Ireland, United Kingdom. 